\title{
Effects of Gasoline Inhalation on Menstrual Characteristics and the Hormonal Profile of Female Petrol Pump Workers
}

\author{
Christopher E. Ekpenyong, Koofreh Davies, Nyebuk Daniel
}

Department of Physiology, Faculty of Basic Medical Sciences, University of Uyo, Uyo, Nigeria.

Email: chrisvon200@yahoo.com

Received May $15^{\text {th }}, 2013$; revised June $28^{\text {th }}, 2013$; accepted July $30^{\text {th }}, 2013$

Copyright (C) 2013 Christopher E. Ekpenyong et al. This is an open access article distributed under the Creative Commons Attribution License, which permits unrestricted use, distribution, and reproduction in any medium, provided the original work is properly cited.

\begin{abstract}
Increasing numbers of young women are employed as gasoline station attendants in most developing countries despite the lack of empirical data on the adverse reproductive health effect of this solvent. This study therefore sought to assess the effects of gasoline inhalation on the serum sex hormone profile and menstrual characteristics of female gasoline station attendants in Nigeria, given the global increase in the rate of infertility and the existing evidence on the reproductive toxicity of gasoline constituents. A site-by-site cross-sectional study of 117 female gasoline pump attendants and 118 age-matched controls was carried out between September 2011 and November 2012. The following 3 instruments were used for data collection: a semi-structured questionnaire, a female sex hormone profile assay and exposure status measures. The prevalence of menstrual disorders among the exposed and unexposed women was $37.2 \%$ and $28.5 \%$ respectively. Exposure to gasoline was significantly associated with disorders in both menstrual cycle length and quantity of flow. Specifically, exposed women had a greater than threefold increased risk of a menstrual disorder, with an odds ratio (OR) of 3.25 for abnormal cycle length and OR of 4.16 for abnormal quantity of flow. In addition, longer duration of exposure ( $>1$ year) was significantly associated with higher likelihood of menstrual disorders. There were also persistent low serum levels of estradiol, and fluctuating levels of other reproductive hormones. Gasoline inhalation may interfere with ovarian functions leading to disordered menstrual characteristics and female sex hormone profiles, as well as future reproductive impairment.
\end{abstract}

Keywords: Adverse Reproductive Outcome; Female Worker; Gasoline Inhalation

\section{Introduction}

In recent years, there has been a significant influx of female workers in petrochemical firms, and a considerable proportion of these workers are of reproductive age [1]. This scenario carries significant public health concern and has been an important issue in occupational medicine [2] due to the potential adverse effects of occupational exposure to toxic gasoline constituents on female reproductive endpoints, especially given the increased rate of infertility in both developed [3] and developing countries.

Among the numerous constituents of petroleum products, gasoline constituents (benzene, toluene, ethyl benzene and xylene (BTEX)) are designated as the most toxic compounds to humans [4]. These compounds are volatile and lipophilic in nature, and workers may be exposed through inhalation, ingestion or dermal routes [5]. These exposures can be accidental or intentional and are insidious in nature [6,7]. It is generally considered that dermal absorption of gasoline does not contribute significantly to systemic toxicity [8].

Evidence, however, favours the view that BTEX in gasoline may be important human reproductive toxins. In addition, the relationship between exposure to these organic solvents and adverse reproductive outcomes, such as congenital malformation, chromosomal abnormalities and altered fertility, has been repeatedly tested and documented in experimental animals [9].

However, the epidemiologic data associating gasoline with human reproductive health, with particular reference to its effect on female sex hormones and menstrual char- 
acteristics, are limited. Gasoline constituents (BTEX) are regarded as reproductive toxicants [10], and as such, they can act as environmental endocrine disruptors [11], which are defined as exogenous agents that can modulate or interfere with the production, release, transport, metabolism, binding, actions and elimination of the natural hormones in the body $[12,13]$. The ovaries are the target organs for injury caused by these reproductive and endocrine toxicants [14], although their effects on other endocrine organs such as the hypothalamus, pituitary, adrenals, thyroid, parathyroid and pancreas are also well documented [15]. For instance, evidence has accumulated that benzene and its analogues affect the luteal functions of female workers in petrochemical industries [16]. In addition, benzene fume inhalation has been shown to affect the hypophysis and the extension of ovarian functional status in rats [17]. Moreover, the documented adverse health effects of gasoline include female infertility, spontaneous abortion, birth defects, and intrauterine growth retardation.

These adverse reproductive health effects may initially be signalled by the presence of altered menstrual characteristics, and the study by Rowland et al. [18] identified long and/or irregular cycles as being associated with infertility and foetal loss during the most recent pregnancy [18]. Menstrual disorders have also been reported among women in occupations such as farmers, health workers, dancers, athletes, semiconductor manufacturers and liquid crystal display workers $[19,20]$, although scant data exist concerning the menstrual characteristics of women working as petrol pump attendants in gasoline stations, despite the influx of a large number of women (at the peak of reproductive age) into this occupation in Nigeria.

Menstrual outcomes are important potential indicators or markers of other health outcomes, such as infertility, osteoporosis, breast and lung cancer, anaemia, pancytopaenia, increased rate of leukaemia, neurological disturbances, and breathlessness, which are also known to be associated with exposure to BTEX compounds [20-22]. Also, in most cases, individuals are unaware of reproductive hazards resulting from these occupational exposures until they are interested in child birth [1]. It was therefore felt that a study to investigate the effect of gasoline inhalation on the menstrual characteristics and hormonal profiles of female petrol pump workers, who receive continuous occupational exposure and whose future reproductive performance depends on the integrity of their reproductive organs, would be valuable.

\section{Material/Methods}

\subsection{Subject and Methods}

This study took place in the Uyo metropolis of South-
South Nigeria between September 2011 and November 2012. Several commercial petrol stations were selected as study sites based on their geographical location to represent the entire study area. Two hundred and thirtyfive female respondents (117 petrol pump workers and 118 age-matched control subjects) participated in this survey.

The inclusion criteria were as follows: age between 18 and 40 years, not pregnant or breast feeding, no use of oral contraceptives during the previous year, no history of menstrual disorder/irregularity prior to employment as a gasoline pump worker, no history of treatment for menstrual disorders prior to employment, no sexually transmitted infections or pelvic inflammatory disease, fertility, no history of any abdominal surgery, good dietary intake and moderate physical activity status for the previous year, normal body mass index and the absence undue perceived stress.

\subsection{Survey Methods}

Three survey instruments were used in this study: a semistructured questionnaire adapted from previous studies on menstrual cycle characteristics [23,24]; assays to measure plasma female sex and other related hormones; and an exposure assessment tool. The questionnaire consisted of two sections and contained open-ended questions and probes aimed at exploring the socio-demographic profile and menstrual characteristics of the respondents.

Section one contained seven open-ended questions structured to obtain information regarding the participants' age (years), educational status, marital status, duration on the job, physical activity status, nutritional habit and presence or absence of perceived stress. The age of the respondents was stratified into 3 groups: 18 $25,26-35$ and $36-40$ years. Educational status was divided into 3 groups according to the level of education attained, i.e., primary, secondary or tertiary education. Marital status was classified as single, married or divorced. Body mass index was calculated as weight/height $\left(\mathrm{kh} / \mathrm{m}^{2}\right)$, and subjects were defined as normal $(<25)$, overweight $(25.0-29.9)$ or obese $(\geq 30)$ according to the WHO classification [25]. Perceived stress was assessed using the perceived stress scale; the values were scored on a 4-point Likert scale and interpreted as no stress ( 0 $1)$, low stress (2 - 3 ) or high stress $(\geq 4)$.

The duration on the job was stratified into two groups: those who had worked for less than one year and those who had worked for more than one year.

Part two of the questionnaire consisted of ten questions aimed at obtaining information on the respondents' past and present obstetric and gynecologic history, with 
special emphasis placed on the age at menarche, contraceptive history and menstrual cycle characteristics (length/duration and quantity of flow) for the previous year. To categorise the respondents' menstrual cycle length, they were asked "how many days are there from the first day of one menstrual period to the first day of the next period?" The answer categories included 24 days or less, 25 - 30 days, 31 - 35 days and greater than 35 days. Based on the answers given, the participants were divided into three groups, including those with a short cycle length (defined as a cycle that last for less than 24 days), those with a long cycle ( $>35$ days) and those with a normal cycle length (24 - 35 days). The choice of these cut-off points was based on previous research into menstrual cycles [23,24].

To estimate the quantity of the menstrual flow, the participants were asked how many menstrual hygiene pads they typically needed to change per day and whether there had been an increase or decrease within the past three months or more.

Those with a noticeable decrease in the number of pads required due to a reduced quantity of flow were grouped as having a scant/light flow, whereas those with a noticeable increase in the number of pads required due to an increase in quantity of flow were grouped as having a heavy menstrual flow. Participants with a normal flow were those with no indication to increase or decrease the number of sanitary pad required during menstruation.

For the female sex hormone profile assay, participant blood samples were obtained from the cubital vein on the arm in the Department of Chemical Pathology of the University of Uyo Teaching Hospital, Uyo, Nigeria. The menstrual cycle phase of the participants when the blood was taken was noted, as the normal levels of these hormones vary according to the cycle phase. Based on the serum levels of the hormones and in comparison to the normal range, according to the cycle phase, the participants were classified as having normal, high or low levels of sex hormones.

The concentration of the BTEX compounds at each of the gasoline stations was assessed and used to monitor the attendants' exposure. Personal samples were collected in sorbent tubes containing activated charcoal (80 - 100 mesh), which were mounted in the breathing zone of the gasoline pump attendants. The air around the breathing zone was drawn through the activated charcoal; it was then absorbed by the carbon disulphide and analysed using gas chromatography (Perkin Elmer Auto System XL GL) with a flame ionisation detector. The instrument was positioned to established contact with the air inhaled by the exposed participants. Similar assessments were repeated few kilometres away from gasoline stations.

\subsection{Statistical Analysis}

Frequencies and percentages were computed for the demographic characteristics of the subjects. The Chisquared test was employed to test the association between menstrual characteristics and exposure to petroleum products.

Furthermore, a logistic regression model was also used to examine the association between exposure to petroleum products and menstrual disorders without and with adjustment for other possible confounders. This analysis was also performed to investigate the effect of exposure duration on menstrual disorders among exposed individuals. Hence, crude and adjusted odd ratios and 95\% confidence intervals were estimated. All of the statistical computations were enhanced using the statistical package for social sciences (SPSS 20.0). P values $<0.05$ were considered to be statistically significant.

\section{Results}

The socio-demographic variables of the 235 women who participated in this study revealed that $117(49.8 \%)$ were exposed and $118(50.2 \%)$ were unexposed. In addition, $37.9 \%$ were between the ages of 18 and 25 years, $54.5 \%$ were between 26 to 35 years, and $7.7 \%$ were between 36 and 40 years.

Of the total participants, $10.6 \%$ had a primary level of education, $85.1 \%$ had a secondary level of education, and $4.3 \%$ had a tertiary level of education. In addition, $71.1 \%$ were single, $27.7 \%$ were married, and $1.3 \%$ was divorced. Those with a perceived high level of stress constituted $51.5 \%$ of the women, whereas $48.5 \%$ demonstrated a low perceived level of stress. In addition, $73.2 \%$ had a normal BMI, 20.0\% were overweight, and $6.8 \%$ were obese (Table 1).

The overall prevalence of menstrual disorders among the exposed and unexposed women was $37.2 \%$ and $28.5 \%$, respectively. The results of the univariate analysis showed that exposure to gasoline inhalation was significantly associated with disorders in both menstrual cycle length $(\mathrm{P}=0.009)$ and quantity of flow $(\mathrm{P}=0.002)$. The prevalence of abnormal cycle length and quantity of flow among the exposed and unexposed women was $27.3 \%$ and $36.8 \%$ for exposed women and $11.9 \%$ and $20.3 \%$ for unexposed women, respectively (Table 2).

The results of the reproductive hormone profile assay showed that the serum levels of estradiol were consistently low in most respondents with menstrual irregularities regardless of the duration of exposure, whereas the levels of other reproductive hormones (FSH, LH, progesterone and prolactin) fluctuated (Table 3).

The multiple logistic regression analysis showed significant associations between exposure to gasoline and 
Table 1. Frequency distributions of demographic characteristics of respondents according to exposure to gasoline.

\begin{tabular}{|c|c|c|c|c|c|}
\hline Demographic Factors & Total $(\mathrm{N}=235)$ & Exposed $(N=117)$ & Unexposed $(\mathrm{N}=118)$ & $X^{2}$ & $P$ value \\
\hline \multicolumn{6}{|l|}{ Age (years) } \\
\hline $18-25$ & 89 (37.9) & $42(35.9)$ & 47 (35.9) & & \\
\hline $26-35$ & $128(54.5)$ & $67(57.3)$ & $61(51.7)$ & 0.78 & 0.677 \\
\hline $36-40$ & $18(7.7)$ & $8(6.8)$ & $10(8.5)$ & & \\
\hline \multicolumn{6}{|l|}{ Education Level } \\
\hline Primary & $25(10.6)$ & $14(12.0)$ & $11(9.3)$ & & \\
\hline Secondary & $200(85.1)$ & $99(84.6)$ & $101(84.6)$ & 0.78 & 0.678 \\
\hline Tertiary & $10(4.3)$ & $4(3.4)$ & $6(5.1)$ & & \\
\hline \multicolumn{6}{|l|}{ Marital Status } \\
\hline Single & $167(71.0)$ & $88(75.2)$ & $79(67.0)$ & & \\
\hline Married & $65(27.7)$ & $27(23.1)$ & $38(32.2)$ & 2.68 & 0.262 \\
\hline Divorced & $3(1.3)$ & $2(1.7)$ & $1(0.8)$ & & \\
\hline \multicolumn{6}{|l|}{ Perceived Stress } \\
\hline High & $121(51.5)$ & $63(53.8)$ & $58(49.2)$ & & \\
\hline Low & $114(48.5)$ & $54(46.2)$ & $60(50.8)$ & 0.35 & 0.556 \\
\hline \multicolumn{6}{|l|}{ BMI } \\
\hline Normal & $172(73.2)$ & 85 (72.6) & 87 (73.7) & & \\
\hline Overweight & $47(20.0)$ & $25(21.4)$ & $22(18.6)$ & 0.460 & 0.794 \\
\hline Obese & $16(6.8)$ & $7(6.0)$ & $9(7.6)$ & & \\
\hline
\end{tabular}

Values in parenthesis are percentages.

Table 2. Frequency distributions of menstrual characteristics of respondents according to exposure.

\begin{tabular}{|c|c|c|c|c|c|}
\hline Outcome & Total $(n=235)$ & Exposed $(n=117)$ & Unexposed $(n=118)$ & $\mathrm{X}^{2}$ & $\mathbf{P}$ \\
\hline \multicolumn{6}{|c|}{ Cycle length (days) } \\
\hline Short & $36(15.3)$ & $24(20.5)$ & $12(10.2)$ & & \\
\hline Long & $10(4.3)$ & $8(6.8)$ & $2(1.7)$ & 9.51 & $0.009^{* *}$ \\
\hline Normal & $189(80.4)$ & $85(72.6)$ & $104(88.1)$ & & \\
\hline \multicolumn{6}{|c|}{ Quantity of flow } \\
\hline Light & $38(16.2)$ & $29(24.8)$ & $9(7.6)$ & \multirow{3}{*}{12.94} & \multirow{3}{*}{$0.002^{* *}$} \\
\hline & & & & & \\
\hline Heavy & $29(12.3)$ & $14(12.0)$ & $15(12.7)$ & & \\
\hline Normal & $168(71.5)$ & $74(63.2)$ & $94(79.7)$ & & \\
\hline
\end{tabular}

${ }^{* *} \mathrm{P}<0.01$, significant at $1 \%$. Values in parenthesis are percentages. 
Table 3. Frequency distributions of the menstrual characteristics and hormonal profiles of respondents according to the duration of exposure.

\begin{tabular}{|c|c|c|c|c|c|c|c|c|c|c|c|}
\hline \multirow{2}{*}{ Outcome } & & \multicolumn{5}{|c|}{$<1$ year $(n=47)$} & \multicolumn{5}{|c|}{$>1$ year $(n=70)$} \\
\hline & & $\mathbf{E}_{2}$ & $\mathbf{P}_{3}$ & LH & FSH & Prolactin & $\mathbf{E}_{2}$ & $\mathbf{P}_{3}$ & LH & FSH & Prolactin \\
\hline \multirow{3}{*}{$\begin{array}{l}\text { Cycle length } \\
\text { Short }(\mathrm{n}=24)\end{array}$} & Normal & $3(37.5)$ & $5(62.5)$ & $5(62.5)$ & $6(75.0)$ & $5(62.5)$ & $8(50)$ & $7(43.8)$ & $8(50)$ & $6(37.5)$ & $8(50)$ \\
\hline & High & $1(12.5)$ & $2(25)$ & $2(25.0)$ & $1(12.5)$ & $2(25)$ & $2(12.5)$ & $4(25)$ & $5(31.2)$ & $4(25)$ & $5(31.2)$ \\
\hline & Low & $4(50)$ & $1(12.5)$ & $1(12.5)$ & $1(12.5)$ & $1(12.5)$ & $6(37.5)$ & $5(31.2)$ & $3(18.8)$ & $6(37.5)$ & $3(18.8)$ \\
\hline \multirow{3}{*}{ Long $(\mathrm{n}=8)$} & Normal & $2(50.0)$ & $2(50.0)$ & $3(75.0)$ & $1(25)$ & $3(75)$ & $1(25)$ & $3(75)$ & $3(75)$ & $2(50)$ & $2(50)$ \\
\hline & High & $0(0)$ & $1(25.0)$ & $0(0)$ & $2(50)$ & $1(25)$ & $1(25)$ & $1(25)$ & $1(25)$ & $1(25)$ & $1(25)$ \\
\hline & Low & $2(50.0)$ & $1(25.0)$ & $1(25.0)$ & $1(25)$ & $0(0)$ & $2(50)$ & $0(0)$ & $0(0)$ & $1(25)$ & $1(25)$ \\
\hline \multirow{3}{*}{ Normal $(n=85)$} & Normal & $25(71.4)$ & $23(65.7)$ & $26(74.3)$ & $30(85.7)$ & $27(77.1)$ & $40(80)$ & $42(84)$ & $45(90)$ & $37(74)$ & $43(86)$ \\
\hline & High & $7(20.0)$ & $8(22.9)$ & $5(14.3)$ & $3(8.6)$ & $5(14.3)$ & $6(12)$ & $5(10)$ & $3(6)$ & $7(14)$ & $5(10)$ \\
\hline & Low & $3(8.6)$ & $4(11.4)$ & $4(11.4)$ & $2(5.7)$ & $3(8.6)$ & $4(8)$ & $3(6)$ & $2(4)$ & $6(12)$ & $2(4)$ \\
\hline \multirow{3}{*}{$\begin{array}{l}\text { Quantity of flow } \\
\text { Heavy }(\mathrm{n}=14)\end{array}$} & Normal & $3(60)$ & $4(80)$ & $3(60)$ & $3(60)$ & $3(60)$ & $5(55.6)$ & $6(66.7)$ & $6(66.7)$ & $6(66.7)$ & $5(55.6)$ \\
\hline & High & $1(20)$ & $1(20)$ & $2(40)$ & $0(0)$ & $2(40)$ & $2(22.2)$ & $1(11.1)$ & $2(22.2)$ & $1(11.1)$ & $3(33.3)$ \\
\hline & Low & $1(20)$ & $0(0)$ & $0(0)$ & $2(40)$ & $0(0)$ & $2(22.2)$ & $2(22.2)$ & $1(11.1)$ & $2(22.2)$ & $1(11.1)$ \\
\hline \multirow{3}{*}{ Light $(\mathrm{n}=29)$} & Normal & $8(57.1)$ & $9(64.3)$ & $7(50)$ & $7(50)$ & $7(50)$ & $7(46.7)$ & $7(46.7)$ & $8(53.3)$ & $8(53.3)$ & $7(46.7)$ \\
\hline & High & $2(14.3)$ & $2(14.3)$ & $3(21.4)$ & $5(35.7)$ & $4(28.6)$ & $3(20)$ & $4(26.6)$ & $4(26.6)$ & $4(26.6)$ & $3(20)$ \\
\hline & Low & $4(28.6)$ & $3(21.4)$ & $4(28.6)$ & $2(14.3)$ & $3(21.4)$ & $5(33.3)$ & $4(26.6)$ & $3(20)$ & $3(20)$ & $5(33.3)$ \\
\hline \multirow{3}{*}{ Normal $(n=74)$} & Normal & $20(71.4)$ & $22(78.6)$ & $23(82.1)$ & $23(82.1)$ & $24(85.7)$ & $34(73.9)$ & $35(76.1)$ & $37(80.4)$ & $39(84.8)$ & $36(78.3)$ \\
\hline & High & $4(14.3)$ & $2(7.1)$ & $3(10.7)$ & $1(3.6)$ & $2(7.1)$ & $5(10.9)$ & $6(13.0)$ & $4(8.7)$ & $4(8.7)$ & $6(13.0)$ \\
\hline & Low & $4(14.3)$ & $4(14.3)$ & $2(7.1)$ & $4(14.3)$ & $2(7.1)$ & $7(15.2)$ & $5(10.9)$ & $5(10.9)$ & $3(6.5)$ & $4(8.7)$ \\
\hline
\end{tabular}

Normal Rang (NR) for Estradiol $\left(\mathrm{E}_{2}\right) 60-150 \mathrm{pg} / \mathrm{ml}$; Progesterone $\left(\mathrm{P}_{3}\right) 0.5-2.3 \mathrm{ng} / \mathrm{ml}$ (Follicular phase) or 2 - $25 \mathrm{ng} / \mathrm{ml}(\mathrm{Luteal}$ phase); Prolactin 1.8 - 19 $\mathrm{ng} / \mathrm{ml}$; FSH $<10 \mathrm{miu} / \mathrm{ml}$ (Follicular phase), 5 - $16 \mathrm{miu} / \mathrm{ml}$ (Midcycle), or $<10 \mathrm{miulml}$ (Luteal phase); LH $<27 \mathrm{miu} / \mathrm{ml}$ (Follicular phase), $34-90 \mathrm{miu} / \mathrm{ml}$ (Midcycle), or $<15 \mathrm{miu} / \mathrm{ml}$ (Luteal phase).

menstrual cycle length $(\mathrm{P}=0.016)$ and quantity of flow $(\mathrm{P}=0.0012)$, after adjustments were made for potential confounders, such as age, marital status, educational level, perceived stress and body mass index. Specifically, exposed women had a greater than three-fold increased risk of a menstrual disorder (odds ratio (OR) adjusted: 3.25 , confidence interval (C.I): 1.347 - 5.781), with an OR of 3.25 for abnormal cycle length and an OR of 4.16 for abnormal quantity of flow. In addition, longer duration of exposure ( $>1$ year) was significantly associated with a higher likelihood (OR: 4.15, C.I: 2.224 - 14.004) of menstrual disorders (Table 4).

Table 5 shows that a higher rate of exposure to inhaled gasoline compounds by petrol pump attendants was detected, as evidence by a higher concentration of these compounds (BTEX) at the location of the meter and in the immediate vicinity of the gasoline stations; in con- trast, decreased concentrations were detected as the distance increased, and these compounds were almost undetectable few kilometres away from the gasoline stations.

\section{Discussion}

The present study observed a higher rate of exposure to gasoline inhalation by gasoline station attendants compared to control individuals. This finding was evidenced by the higher concentration of gasoline constituents (specifically BTEX compounds) at the location of the meter point and within the immediate vicinity of the gasoline stations in comparison to few kilometres away from the gasoline stations.

Findings also indicated that exposed participants had a significantly higher prevalence of menstrual disorders in 
Table 4. Logistic regression showing associations between exposure status and duration of exposure to gasoline inhalation and menstrual disorders of the participants (OR and 95\% C.I).

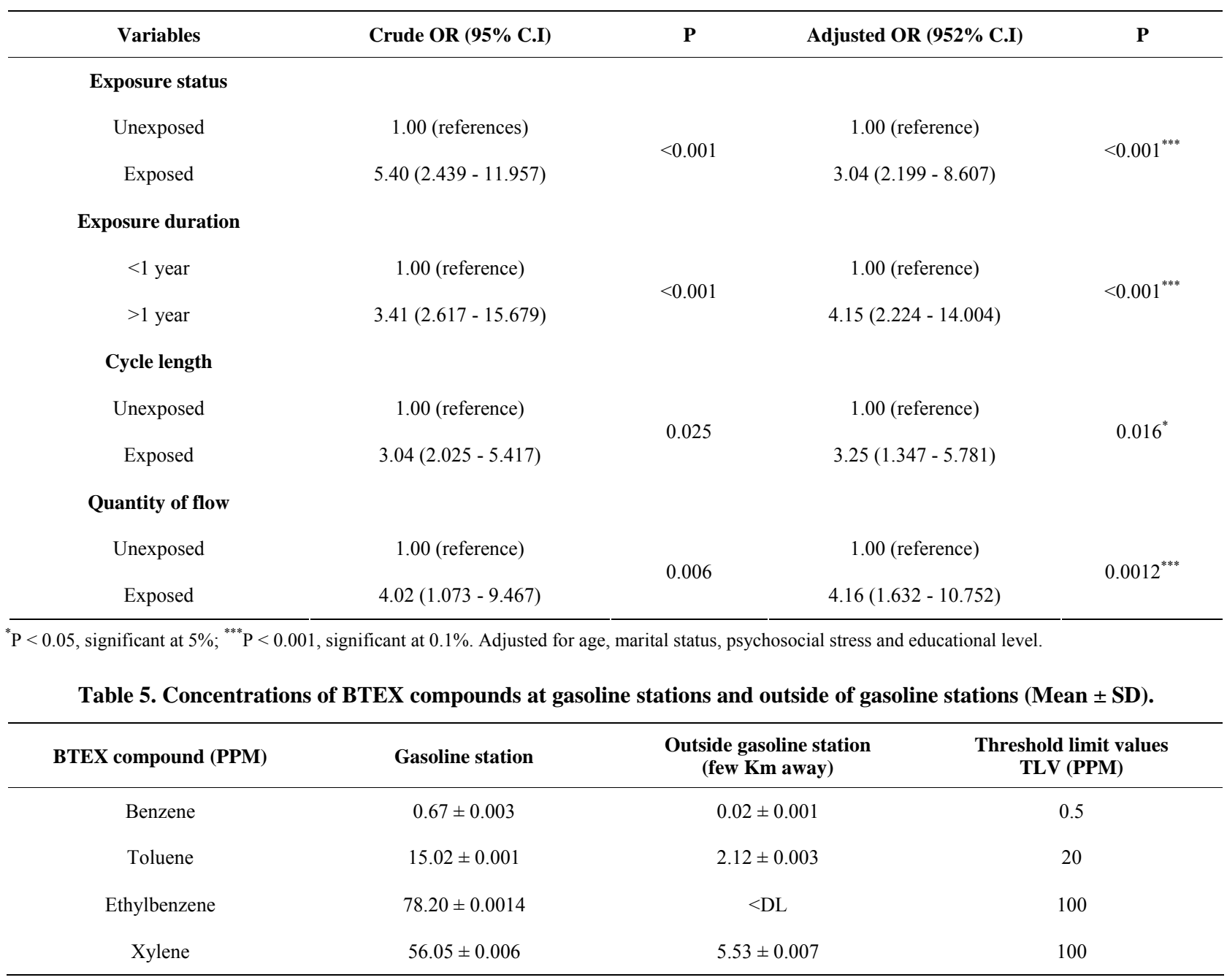

DL: Detection Limit. The detection limits for the BTEX compounds listed above were 0.07, 0.06, 0.05 and 0.05 PPM, respectively [4].

comparison to unexposed women. The menstrual disorders observed among the exposed were more prevalent among those who had been exposed for more than 1 year. Associated with these menstrual disorders were persistently low serum estradiol $\left(E_{2}\right)$, and fluctuating levels of other reproductive hormones ( $\mathrm{LH}, \mathrm{FSH}$, prolactin and progesterone). These hormonal patterns modelled the previous pattern identified in women with accelerated follicular depletion with intact hypothalamic pituitary action [26]. We therefore hypothesised that inhaled gasoline compounds (specifically BTEX compounds) may affect ovarian function. BTEX compounds have been designated the most toxic constituents of gasoline for humans [4], particularly in regards to their effect on the reproductive system, as the ovaries are the main target organ for injury resulting from these reproductive and endocrine toxicants [14]. This assertion is in line with existing evidence demonstrating a direct action of BTEX on ovarian structures and functions, thereby interfering with the release of ovarian hormones $\left(\mathrm{E}_{2}\right.$ and $\left.\mathrm{P}_{3}\right)$ and the ovarian response to physiological hypothalamic-pituitary action [27]. Existing research [16,28] further indicates an association between benzene and ovarian hypo- and hyperplasia, as well as reductions in the duration of the luteal phase of the menstrual cycle. Benzene is also known to reduce the release of estradiol prior to ovulation, as well as the release of FSH at the early follicular phase and the release of progesterone at the early luteal phase [16].

Toluene inhalation has been shown to increase the incidence of maternal and foetal morbidity and embryonic malformation [29], and this compound also reduces the hypothalamic level of gonadotropin releasing hormone $(\mathrm{GnGH})$ and the plasma level of gonadotropins [27]. In 
addition, xylene was shown to decrease plasma levels of progesterone and estradiol. Although these adverse reproductive health effects are known and well documented, it is noteworthy that they are not always present in all exposed individuals. For example, and similar to previous studies, we found that not all exposed gasoline workers developed abnormal menstrual characteristics or deranged reproductive hormone profiles. There are multiple interpretations for this finding, including inter-individual differences due to variations in the pulmonary absorption, distribution, action, metabolism and excretion of inhaled gasoline compounds, which further depend on blood gas values and the fat-blood partition coefficient [30].

Nonetheless, it is recognised that such differences could be due to the effects of other un-modifiable confounders, including the age of the participants. In the present study, $36 \%, 6.8 \%$ and $57.3 \%$ of the exposed participants were within the perimenarchial, premenopausal and peak reproductive ages, respectively.

Several lines of evidence have shown that changes in hormonal patterns, and hence menstrual irregularities with age, may be a consequence of the age-related decline in ovarian follicle reserve, leading to a decrease in ovarian factors (e.g., inhibin B) important for the regulation of ovarian pituitary feedback and a secondary decline in luteal function [31]. Such changes are common among women near the perimenarchial and premenopausal ages. The effects of inhaled solvents may also have been exacerbated in subjects within these age limits, with less of an effect for those within peak reproductive age.

In a similar manner, earlier studies $[27,32,33]$ showed that the deleterious effects of a potentially toxic solvent on the endocrine system generally require longer durations of exposure and repeated absorption [15]. This may provide an explanation for the positive correlation between the duration of exposure and the severity of the reproductive dysfunction present in a subset of the female workers in the present study. Moreover, as in previous studies that compared other constituents of gasoline, benzene was found to be present in concentrations high enough to cause adverse reproductive health outcomes, and the plausibility of these findings is supported by the study of Sexton et al. [34].

According to that study, exposure to benzene above the threshold limit value was associated with higher adverse reproductive effects [34]. This assertion was later supported by the study of Mehrjerdi et al. [35], which was conducted at gas stations in the Yaza province. These authors found that, compared to other constituents of BTEX compounds, benzene was present in concentrations above the threshold limit value (0.5 PPM). In con- trast, toluene, ethylbenzene and xylene demonstrated mean concentrations below the threshold limit [4], as observed in the present study.

Previous studies have proposed several conflicting opinions regarding the putative mechanisms of action of endocrine disrupters such as BTEX compounds that lead to adverse reproductive outcomes. While some of these authors have speculated on the direct effect of endocrine disrupters on steroidogenesis [2], by directly interfering with steroidogenic enzymes and acting as potent enzyme inhibitors to produce a low concentration of female sex hormones, others found less consistent or no effect on steroidogenic enzymes and hence hormone synthesis [13].

These apparently conflicting observations can be resolved when certain facts are considered, including differences in chemical properties and the molecular properties and pharmacodynamics of different endocrine disrupters. Other possible mechanisms include solvent interference with the hepatic microsomal enzyme system responsible for endogenous hormone metabolism [15]. In addition, Guisti et al. [35] proposed the alteration of uterine structure as a potential mechanism, and according to Kim et al. [2], BTEX compounds may exert their actions at the level of the hypothalamic-pituitary axis to interfere with trophic hormones secretion and lead to down-regulation of gonadotropin releasing hormone (GnRH), GnRH receptors and pituitary-1 receptor mRNA levels. In particular, these authors [2] demonstrated that injection of toluene and xylene led to a significant reduction in the serum concentrations of GnRH, GnRH receptor and pituitary-1 mRNA in experimental animals [2]. Furthermore, knowledge of the different levels of action of endocrine disrupters may help differentiate hypothalamic-pituitary dysfunction from direct germ cell injury [19]; in hypothalamic-pituitary dysfunction, the serum levels of gonadotropin hormones (FSH and LH) are low, whereas in germ cell affectation, high FSH levels with associated low $E_{2}$ serum concentrations are typical.

In support of the persistently low levels of $E_{2}$ but fluctuating levels of FSH and $\mathrm{LH}$ observed in most exposed participants with menstrual disorders in the present study, it may be accurate to conclude, in agreement with previous studies [27], that BTEX compounds interfere with the ovarian cycle (particularly during the follicular phase) in individuals exposed to gasoline fumes. The differences in the serum levels of FSH and LH observed among exposed participants may be ascribed to differences in the regulation of FSH and $\mathrm{LH}$ secretion and diminished $\mathrm{E}_{2}$ concentrations at the hypothalamic or pituitary levels or differential sensitivity to gonadotropin releasing hormones [36]. 


\section{Conclusion}

The present study provides additional evidence to support the positive association between exposure to gasoline inhalation and the development of adverse reproductive endpoints, including menstrual and reproductive hormone profile abnormalities suggestive of ovarian functional affectations, specifically during the follicular phase. However, this association is likely influenced by several modifiable and un-modifiable confounders.

\section{REFERENCES}

[1] S. Kumar, "Occupational Exposure Association with Reproductive Dysfunction," Journal of Occupational Health, Vol. 46, No. 1, 2004, pp. 1-19. doi:10.1539/joh.46.1

[2] D. H. Kim, H. Lee, C. K. Lee, D. S. Kang, J. H. Kin, J. T. Lee, J. H. Chun and C. K. Lee, "Effects of Toluene, Xylene and Trichloroethylene on the Regulation of GnRH, RnRH Reception and Pit-1 Gene Expression in male Rat Hypothalamus and Pituitary," Korean Journal of Occupational and Environmental Medicine, Vol. 10, No. 2, 1998, pp. 267-281.

[3] B. Runnebaum, T. Rabe, M. Sillem and W. Eggert-Kruse, "Infertility," In: B. Runnebaum and T. Rabe, Eds., Gynecological Endocrinology and Reproductive Medicine, Springer-Verlag, New York, 1997, pp. 107-164. doi:10.1007/978-3-642-60390-7

[4] M. R. Azari, Z. N. Konjin, F. Z. Salehpour and M. D. Seyedi, "Occupational Exposure of Petroleum Depot workers to BTEX Compounds," International Journal of Occupational and Environmental Medicine, Vol. 3, No. 1, 2012, pp. 39-44.

[5] R. Cecil, R. J. Ellison, K. Larminaa, S. A. Margary, J. M. Mata and L. Morcillo, "Exposure Profile: Gasoline," CONCAWE Report, CONCAWE, Brussels, 1997.

[6] S. C. Edminster and M. J. Bayer, "Recreational Gasoline Sniffing, Acute Gasoline Intoxication and Latent Organolead Poisoning: Case Reports and Literature Review," Journal of Emergency Medicine, Vol. 3, No. 5, 1985, pp. 365-370. doi:10.1016/0736-4679(85)90321-X

[7] S. Cairney, P. Maruff, C. Burns and B. Currie, "The Neurobehavioural Consequences of Petrol (Gasoline) Sniffing," Neuroscience and Biobehavioural Reviews, Vol. 26, No. 1, 2002, pp. 81-89. doi:10.1016/S0149-7634(01)00040-9

[8] W. Machle, "Gasoline Intoxication," Journal of the American Medicinal Association, Vol. 177, No. 23, 1941, pp. 1965-1971. doi:10.1001/jama.1941.02820490039013

[9] C. C. Ugwoke, E. D. Nwobodo, P. Unekwe, M. Odike, S. T. Chukwuma and G. Amilo, "The Reproductive Dysfunction Effects of Gasoline Inhalation in Albino Rats," Nigerian Journal of Physiological Sciences, Vol. 20, No. 1-2, 2005, pp. 54-57.

[10] L. Fraier and M. L. Hage, "Reproductive Hazard of Workplaces," Wiley, New York, 1997.

[11] C. N. Humfrey and L. L. Smith, "Endocrine Disrupting
Chemicals," In: P. W. Harvey, K. C. Rush and A. Cockborn, Eds., The Evidence for Human Health Effects in Endocrine and Hormonal Toxicity, John Wiley and Sons, New York, 1999, p. 421.

[12] R. J. Kavlock, et al., "Research Needs for the Risk Assessment of Health and Environmental Disruptors: A Report of U.S. EPA-Sponsored Workshop," Environmental Health Perspectives, Vol. 104, No. S4, 1996, pp. 715-740.

[13] P. Nicolopoulou-Stamati and M. A. Pitsos, "The Impact of Endocrine Disrupters on the Female Reproductive System," Human Reproductive Update, Vol. 7, No. 3, 2000, pp. 323-330. doi:10.1093/humupd/7.3.323

[14] D. R. Mattison, D. R. Plowehalk, M. J. Meadow, A. Z. Al-Juburi, J. Gardy and A. Malek, "Reproductive Toxicity: Male and Female Reproductive Systems as Targets for Chemical Injury," Medical Clinics of North America, Vol. 74, No. 2, 1990, pp. 391-411.

[15] Y. Verma and S. V. Rana, "Endocrinal Toxicity of Industrial Solvents-A Mini Review," Indian Journal of Experimental Biology, Vol. 47, No. 7, 2009, pp. 537-549.

[16] H. Chen, L. Song, X. Wang and S. Wang, "Effect of Exposure to Low Concentration of Benzene and Its Analogues on Luteal Function of Female Workers," Wei Sheng Yan Jiu, Vol. 29, No. 6, 2000, pp. 351-353.

[17] V. G. Matysiak, "The Effect of Benzene Fumes on the Functional Activity of Hypophysis, Adrenals and Ovaries of White Rats under Experimental Condition," Godisen Zbornik na Medicinskiot Fakultet vo Skopje, Vol. 14, 1968, pp. 98-100.

[18] S. Rowland, D. D. Barid, G. Longs, S. D. Wegienka, M. Harlow and D. P. Alavanja, "Influence of Medical Conditions and Life Style Factors on the Menstrual Cycle," Epidemiology, Vol. 13, No. 6, 2002, pp. 668-674. doi:10.1097/00001648-200211000-00011

[19] M. Paul, "Occupational Reproductive Hazards," The Lancet, Vol. 349, No. 9062, 1997, pp. 1385-1388. doi:10.1016/S0140-6736(96)07217-0

[20] C. C. Lin, C. N. Huang, Y. H. Hwang, J. D. Wang, S. P. Weng, R. H. Shie and P. C. Chem, "Shortened Menstrual Cycles in LCD Manufacturing Workers," Occupational Medicine, Vol. 63, No. 1, 2013, pp. 45-52. doi:10.1093/occmed/kqs 172

[21] G. Pandya, A. Gavane and V. Kondawar, "Assessment of Occupational Exposure to VOCs at the Gantry Gasoline terminal," Environmental Science and Engineering, Vol. 48, No. 3, 2006, pp. 175-182.

[22] N. Hopf, J. Kirkeleit, M. Bratveit, P. Succop, G. Talaska and B. E. Moen, "Evaluation of Exposure Biomarkers in Offshore Workers Exposed to Low Benzene and Toluene Concentrations," International Archives of Occupational and Environmental Health, Vol. 85, No. 3, 2011, pp. 261271.

[23] Y. Lui, E. B. Gold, B. L. Lasley and W. O. Johnson, "Factors Affecting Menstrual Cycle Characteristics," American Journal of Epidemiology, Vol. 160, No. 2, 2004, pp. 131-140. doi:10.1093/aje/kwh188 
[24] G. Toft, A. Axmon, C. Lindh, A. Giwereman and J. P. Bonde, "Menstrual Cycle Characteristics in European and Inuit Women Exposed to Persistent Organochlorine Pollutants," Human Reproduction, Vol. 23, No. 1, 2008, pp. 193-200. doi:10.1093/humrep/dem349

[25] World Health Organization (WHO), "Obesity: Preventing and Managing the Global Epidemic: Environmental and Societal Influences,” WHO, Geneva, 2000, pp. 118-122.

[26] M. J. Faddy, R. G. Gasden, A. Gougeon, S. J. Richardson and J. F. Nelson, "Accelerated Disappearance of Ovarian Follicles in Mid-Life: Implication for Forecasting Menopause," Human Reproduction, Vol. 7, No. 10, 1992, pp. 1342-1346.

[27] V. Sirotkin, A. Kâdas, A. Balâžá, Z. Baková, Z. Halim, A. Harrath, A. V. Makarevich, A. Kolesárova, P. Chrenek, J. Kotwica and T. Tóth, "Influence of Petrochemical Industry Environment Contaminants on Animal Ovarian Cells," Journal of Microbiology, Biotechnology and Food Sciences, Vol. 32, No. 2, 2012, pp. 517-525.

[28] R. R. Maronpot, "Ovarian Toxicity and Carcinogenicity in Eight Recent National Toxicology Program Studies," Environmental Health Perspectives, Vol. 73, 1987, pp. 125-130. doi:10.1289/ehp.8773125

[29] J. H. Hannigan and E. S. Bowen, "Reproductive Toxicology and Teratology of Abused Toluene," Systems Biology in Reproductive Medicine, Vol. 56, No. 2, 2010, pp. 184-200.

[30] A. Sato and T. Nkajima, "Pharmacokinetics of Organic Solvent Vapors in Relation to Their Toxicity," Scandinavian Journal of Work, Environment and Health, Vol. 13,
No. 2, 1987, pp. 81-93.

[31] D. M. Robertson, G. E. Hale, D. Jolley, I. S. Fraser, C. L. Hughes and H. G. Burger, "Interrelationships between Ovarian and Pituitary Hormones in Ovulatory Menstrual Cycles across Reproductive Age," Journal of Clinical Endocrinology and Metabolism, Vol. 91, No. 1, 2009, pp. 138-144.

[32] M. Mukhametova and Vozovaya, "Reproductive Power and the Incidence of Gynecological Disorders in Female Workers Exposed to the Combined Effect of Benzene and Chlorinated Hydrocarbons," Gig Tr Prof Zabol, Vol. 16, 1972, pp. 6-9. (in Russian)

[33] X. Y. Huang, "Influence on Benzene and Toluene to Reproductive Functions of Female Workers in Leather Shoe Making Industry," Chinese Journal of Preventive Medicine, Vol. 25, No. 2, 1991, pp. 89-91.

[34] K. Sexton, S. H. Linder, D. Marko, H. Bethal and P. J. Lupo, "Comparative Assessment of Air Pollution-Related Health Risks in Houston," Environmental Health Perspectives, Vol. 115, No. 10, 2007, pp. 1388-1393.

[35] R. M. Guisti, K. Iwamoto and E. E. Hatch, "Diethylstilbestrol Revisited: A Review of the Long-Term Health Effects," Annals of Internal Medicine, Vol. 122, No. 10, $1995,778-788$. doi:10.7326/0003-4819-122-10-199505150-00008

[36] B. M. Sherman and S. G. Koreman, "Hormonal Characteristics of Human Menstrual Cycle throughout Reproductive Life," The Journal of Clinical Investigation, Vol. 55, No. 4, 1975, pp. 699-706. doi:10.1172/JCI107979 